\title{
An Experimental Investigation of the Laminar Flamelet Concept for Soot Properties
}

\author{
F.J. Diez ${ }^{1}$, C. Aalburg ${ }^{2}$, P.B. Sunderland ${ }^{3}$, D.L. Urban $^{4}$, Z.-G. Yuan ${ }^{5}$, G.M. Faeth ${ }^{6}$ \\ ${ }^{1}$ Rutgers University, Piscataway, NJ, 08854, USA \\ ${ }^{2,6}$ University of Michigan, Ann Arbor, MI, 48109, USA \\ ${ }^{3}$ University of Maryland, College Park, MD, 20742, USA \\ ${ }^{4,5}$ NASA Glenn Research Center, Cleveland, OH, 44135, USA
}

The soot properties of round, nonbuoyant, laminar jet diffusion flames are described, based on experiments at microgravity carried out on orbit during three flights of the Space Shuttle Columbia, (Flights STS-83, 94 and 107). Experimental conditions included ethyleneand propane-fueled flames burning in still air at an ambient temperature of $300 \mathrm{~K}$ and ambient pressures of 35-100 kPa. Measurements included soot volume fraction distributions using deconvoluted laser extinction imaging, and soot temperature distributions using deconvoluted multiline emission imaging. Flowfield modeling based on the work of Spalding is presented. The present work explores whether soot properties of these flames are universal functions of mixture fraction, i.e., whether they satisfy soot state relationships. Measurements are presented, including radiative emissions and distributions of soot temperature and soot volume fraction. It is shown that most of the volume of these flames is bounded by the dividing streamline and thus should follow residence time state relationships. Most streamlines from the fuel supply to the surroundings are found to exhibit nearly the same maximum soot volume fraction and temperature. The radiation intensity along internal streamlines also is found to have relatively uniform values. Finally, soot state relationships were observed, i.e., soot volume fraction was found to correlate with estimated mixture fraction for each fuel/pressure selection. These results support the existence of soot property state relationships for steady nonbuoyant laminar diffusion flames, and thus in a large class of practical turbulent diffusion flames through the application of the laminar flamelet concept.

\section{Nomenclature}

$$
\begin{aligned}
& =\text { nozzle diameter }(\mathrm{mm}) \\
& =\text { mixture fraction } \\
& =\text { soot volume fraction }(\mathrm{ppm}) \\
& =\text { stoichiometric mixture fraction } \\
& =\text { mass flow rate } \mathrm{mg} / \mathrm{s} \\
& =\text { fuel velocity at nozzle } \\
& =\text { luminous flame length }(\mathrm{mm}) \\
& =\text { residence time in flame }(\mathrm{s}) \\
& =\text { residence time at centerline } \\
& =\text { axial distance }
\end{aligned}
$$

${ }^{1}$ Assist. Professor, Dept. Mechanical and Aerospace Eng., AIAA Member.

${ }^{2}$ Currently at GE Global Research, Munich, Germany.

${ }^{3}$ Assist. Professor, Dept. of Fire Protection Engineering, AIAA Senior Member.

${ }^{4}$ Chief, Combustion and Reacting Systems Branch, AIAA Senior Member.

${ }^{5}$ Staff Scientist, National Center for Space Exploration Research, AIAA Senior Member.

${ }^{6}$ (deceased) Professor, Dept. Aerospace Eng., AIAA Fellow. 


\section{Introduction}

Soot reaction properties in flames represent an important unsolved combustion problem having significant relevance to society. For example, particulate soot emitted as a pollutant from combustion processes causes more deaths than any other combustion-generated pollutant, e.g., it is responsible for roughly 60,000 premature deaths each year in the U.S. alone. In addition, carbon monoxide emissions that result as a direct by-product of particulate soot emissions cause most deaths in unwanted fires, e.g., it is responsible for roughly 4,000 deaths each year in the U.S. alone. Furthermore, continuum radiation from particulate soot is mainly responsible for the growth and spread of unwanted fires, which involves roughly 5,000 deaths each year in the U.S. alone. Finally, limited understanding of the complex processes that cause a solid material, particulate soot, to form in the high-temperature regions of flames that normally are associated with the combustion of solid flammable materials, represents a major impediment to the development of robust methods of computational combustion. Taken together, these observations amply motivate the study of soot processes in flames.

Soot processes in turbulent nonpremixed (diffusion) flames are of greatest practical interest, however, direct study of soot processes in turbulent flames is not feasible using either existing or anticipated technology. Consequently, laminar diffusion flames generally are used as more tractable model flame systems to study processes relevant to turbulent diffusion flames. Prior work has shown that results for laminar flames can be directly relevant to turbulent diffusion flames. In particular the known similarities between the gas-phase properties of these two flame systems that has been responsible for the development of the widely-recognized laminar flamelet concept, where turbulent flames are treated as a collection of laminar flamelets. ${ }^{1,2}$ Unfortunately, buoyant laminar diffusion flames have not been found to have corresponding utility for studying processes of particulate matter in flames such as soot. Thus, a major objective of the present investigation was to study soot processes in nonbuoyant round laminar diffusion flames in an effort to determine if the laminar flamelet concept can be applied to soot properties in nonbuoyant laminar diffusion flames.

\section{Objectives}

The use of state relationships for scalar properties, including soot properties, in conjunction with the conservedscalar formalism and the laminar flamelet concept for turbulent flames, offers a way to resolve problems of limited information concerning soot processes in flames and the computational intractability of detailed mechanisms of soot formation and oxidation in flames. Unfortunately, steady buoyant laminar diffusion flames do not have the same utility for finding state relationships for soot properties in diffusion flames as they do for finding state relationships for other scalar properties in diffusion flames. The underlying hypothesis of this experiment is that nonbuoyant laminar diffusion flames offer a means to measure soot properties that is not possible in buoyant flames.$^{3-5}$ Groundbased efforts to study reduced-buoyancy flames were unable to provide the gravitational environment and residence time needed for these studies. ${ }^{6-8}$ To this end, an attempt was made to conduct experiments to evaluate the potential existence of soot property state relationships by observing soot-containing nonbuoyant laminar jet diffusion flames at long-duration microgravity conditions on board the Space Shuttle Columbia (during Flights STS-83 and STS-94). Unfortunately, the flames observed during these experiments had relatively long characteristic residence times which resulted in excessive radiative heat losses leading to flame quenching and tip-opening phenomena that are not representative of typical laminar flamelet conditions in practical turbulent diffusion flames. In view of these results, additional observations of soot-containing steady nonbuoyant laminar jet diffusion flames were undertaken at microgravity on board the orbiting Space Shuttle Columbia during Flight STS-107, with the following specific objectives:

1. Measure soot and flame properties for various fuels, fuel flow rates, burner diameters and pressures in still air environments considering steady nonbuoyant laminar jet diffusion flames having small radiative heat losses.

2. Exploit the new measurements to develop a simplified analytical description of the structure of nearlyadiabatic, steady, nonbuoyant, laminar, jet diffusion-flames based on the analysis of Spalding. ${ }^{9}$

3. Exploit the soot temperature and soot volume fraction measurements to determine whether soot property state relationships exist within nonbuoyant and nearly adiabatic steady laminar diffusion flames, implying that these flames are the proper paradigm for soot processes in practical turbulent diffusion flames through the widely recognized laminar flamelet concept of turbulent diffusion flames. 


\section{Experimental Methods}

\section{Test Conditions}

Test conditions for flames analyzed from Space Shuttle Columbia Flights STS-83, STS-94 and STS-107 are summarized in Table 1. Details of the experimental design are in Urban et al. ${ }^{10}$ and the operating conditions are discussed in detail in Aalburg et al. ${ }^{11}$ Laminar-jet diffusion flames were stabilized at the exit of a round fuel nozzle located along the axis of a windowed cylindrical chamber. The chamber had a diameter of $400 \mathrm{~mm}$, a maximum length of $740 \mathrm{~mm}$, and an internal volume of $0.082 \mathrm{~m}^{3}$, and was operated at pressures of 35-130 kPa. The chamber was filled with oxygen/nitrogen mixtures to provide the nominal composition of dry air ( $21 \pm 1 \%$ oxygen by volume). Owing to the sealed chamber, the pressure, temperature, and composition of the gas surrounding the test flames all varied gradually during flame burning periods. The greatest change involved the composition of the gas within the chamber; however, test conditions were controlled so that the maximum oxygen consumption generally did not exceed $2 \%$ by volume during the experiments. One exception was test $04 \mathrm{E} 107$, involving an ethylene/ air flame at a total pressure of $49 \mathrm{kPa}$ that had an unusually large fuel flow rate that yielded a correspondingly long flame (up to $140 \mathrm{~mm}$ long) where the maximum oxygen consumption reached $4.0 \%$. The initial composition of the air within the test chamber was maintained at $21 \%$ oxygen by volume by venting the test chamber to space and adding fresh dry air prior to each test.

Over the entire test series, four fuel nozzles consisting of constant diameter cylindrical stainless-steel tubes having inside diameters of $0.40,0.80,1.60$, and $2.70 \mathrm{~mm}$ and lengths of $148 \mathrm{~mm}$ from the inlet plenum were used. The inlets of the nozzles had flow straighteners to prevent swirl, whereas the overall length-to-diameter ratios of the passages were greater than 55:1, which was sufficient to yield fully developed laminar pipe flow at the nozzle exit (jet exit Reynolds numbers of 57671). The test fuels were stored in cylinders and were delivered to the nozzles through a solenoid valve, a mass flow rate controller and a flow limiting orifice. The flames were ignited by a hot wire coil that was retracted from the nozzle exit once ignition was complete.

\section{Instrumentation}

Flame operation was monitored by making the following measurements: fuel flow rate with an accuracy of $0.8 \%$, fuel temperatures at the nozzle inlet with an accuracy of $\pm 1.5 \mathrm{~K}$, chamber pressures with an accuracy of $1.2 \%$, and Table 1 . Summary of the test flames. ${ }^{\text {a }}$

\begin{tabular}{|c|c|c|c|c|c|c|c|c|c|}
\hline Test $^{b}$ & Fuel & $\begin{array}{c}\text { Sooting } \\
\text { Condition }^{\mathrm{c}}\end{array}$ & $\begin{array}{c}d \\
\mathrm{~mm}\end{array}$ & $\begin{array}{c}p \\
\mathrm{kPa}\end{array}$ & $\begin{array}{c}m \\
\mathrm{mg} / \mathrm{s}\end{array}$ & $\begin{array}{c}u_{0} \\
\mathrm{~m} / \mathrm{s}\end{array}$ & $R e$ & $\begin{array}{c}L_{f} \\
\mathrm{~mm}\end{array}$ & $\begin{array}{c}\text { time }^{\mathrm{d}} \\
\mathrm{s}\end{array}$ \\
\hline \multicolumn{10}{|c|}{ ATTACHED FLAMES } \\
\hline 41E107 & $\mathrm{C}_{2} \mathrm{H}_{4}$ & SC & 0.8 & 100 & 0.65 & 1.12 & 98 & 17.1 & 254 \\
\hline 17E94 & $\mathrm{C}_{2} \mathrm{H}_{4}$ & SP & 1.6 & 35 & 1.34 & 1.69 & 100 & 34.0 & 66 \\
\hline 2E94 & $\mathrm{C}_{2} \mathrm{H}_{4}$ & SP & 1.6 & 50 & 0.76 & 0.67 & 57 & 17.7 & 32 \\
\hline 3E94 & $\mathrm{C}_{2} \mathrm{H}_{4}$ & SP & 1.6 & 50 & 1.29 & 1.14 & 97 & 36.5 & 91 \\
\hline $3 \mathrm{E} 83^{\mathrm{e}}$ & $\mathrm{C}_{2} \mathrm{H}_{4}$ & SE & 1.6 & 50 & 1.84 & 1.63 & 138 & 63.0 & 91 \\
\hline 46Р107 & $\mathrm{C}_{3} \mathrm{H}_{8}$ & SC & 0.8 & 99 & 0.53 & 0.59 & 100 & 15.8 & 254 \\
\hline 8P107 & $\mathrm{C}_{3} \mathrm{H}_{8}$ & SE & 0.8 & 100 & 1.21 & 1.33 & 229 & 32.1 & 223 \\
\hline \multicolumn{10}{|c|}{ LIFTED FLAMES } \\
\hline 52E107 & $\mathrm{C}_{2} \mathrm{H}_{4}$ & SC & 0.4 & 99 & 1.51 & 10.55 & 453 & 35.9 & \\
\hline 3E107 & $\mathrm{C}_{2} \mathrm{H}_{4}$ & & 0.8 & 47 & 1.12 & 4.04 & 168 & & \\
\hline 5E107 & $\mathrm{C}_{2} \mathrm{H}_{4}$ & SC & 0.8 & 48 & 1.99 & 7.17 & 299 & 38.6 & \\
\hline 4E107 & $\mathrm{C}_{2} \mathrm{H}_{4}$ & & 0.8 & 49 & 3.96 & 14.27 & 595 & & \\
\hline 54P107 & $\mathrm{C}_{3} \mathrm{H}_{8}$ & SP & 0.4 & 99 & 1.77 & 7.87 & 671 & 50.0 & \\
\hline 7P107 & $\mathrm{C}_{3} \mathrm{H}_{8}$ & $\mathrm{SC}$ & 0.8 & 48 & 0.99 & 2.27 & 188 & 26.1 & \\
\hline
\end{tabular}

${ }^{\mathrm{a}}$ Many entries here are reproduced from Aalburg et al. ${ }^{5}$

${ }^{\mathrm{b}} \mathrm{E}$ is ethylene, $\mathrm{P}$ is propane, and numbers 83, 94, and 107 denote missions STS-83, STS-94, and STS-107.

c All flames had closed tips. SC is soot containing, SP is smoke point, and SE is soot emitting.

${ }^{\mathrm{d}}$ Time is defined as the elapsed time between ignition and image acquisition.

e Note that this flame's identifier was 02E in Urban et al. ${ }^{10}$ chamber gas temperatures (far from the flames) with an accuracy of $\pm 1 \mathrm{~K}$. These measurements were recorded at a frequency of roughly $1 \mathrm{~Hz}$. Soot-luminosity boundaries and flame-sheet locations were measured from images obtained using color CCD video cameras (Hitachi Model KP-0553 during flights STS-83 and STS-94, and Panasonic Model WV-CD612 during flight STS-107). The cameras had a $125 \times 164 \mathrm{~mm}$ field of view and a depth of field of $25 \mathrm{~mm}$ centered on the flame axis. The spatial resolution of recorded images was better than $0.3 \mathrm{~mm}$. Flame images were recorded at 30 images/s. Measured luminous flame lengths and diameters have estimated experimental uncertainties (95\% confidence) that are less than $10 \%$. 
Soot volume fraction distributions were obtained by deconvoluting laser extinction images for chord-like paths through the flames using methods developed by Greenberg and $\mathrm{Ku} .{ }^{12}$ The laser source was a diode laser yielding $1 \mathrm{~mW}$ of optical power at $634 \mathrm{~nm}$ coupled though an optical fiber. The laser beam then passed through a custom apodizing filter (to reduce intensity variations) and was expanded to a $50 \times 80 \mathrm{~mm}$ beam that was collimated by an off-axis parabola before it passed through the flame. The intensity variations across the field of view were less than $75 \%$ with the majority of the variation outside of the region occupied by the flame. The signal transmitted though the flame was collected by a decollimator equipped with a laser line filter (1 - $2 \mathrm{~nm}$ FWHM) and a $3.8 \mathrm{~mm}$ diameter spatial filter before being recorded by a charge-coupled device (CCD) video camera (Panasonic GP-MF552). The camera was oriented to provide 302 pixels over the $80 \mathrm{~mm}$ field of view along the flame axis and 484 pixels normal to the flame axis. The laser was adjusted to bring the intensity maximum in the field of view just below saturation of the CCD camera to allow optimum use of the 8-bit camera sensitivity. Spatial resolution of the imaging system was better than $0.3 \mathrm{~mm}$. Background measurements of the laser beam intensity distribution were made with no flame present before and after each run. The extinction measurements were analyzed assuming Rayleigh scattering from primary soot particles with refractive indices from Dalzell and Sarofim. ${ }^{13}$

Soot temperature distributions were obtained by deconvoluting spectral radiation intensities for chord-like paths through the flames. The procedure involved considering the $650 / 850 \mathrm{~nm}$ line pair. The flame images were observed using two CCD cameras(Panasonic GP-MF552) with appropriate interference (10 nm FWHM) filters in addition to neutral density filter (to control overall signal levels) in the optical path. Two cameras were mounted side-by-side and were oriented to provide 197 pixels over the $80 \mathrm{~mm}$ field of view along the flame axis and 78 pixels over the $20 \mathrm{~mm}$ wide region that includes the soot-containing region. The integration time of the cameras was controlled to enable optimal use of the 8-bit detectors. The spatial resolution was better than $0.4 \mathrm{~mm}$. Camera response at the two wavelengths was calibrated with a blackbody source. The measurements were analyzed assuming Rayleigh scattering from the soot particles similar to the extinction measurements.

\section{Results}

A summary of selected test flames observed during Space Shuttle Columbia Flights STS-83, STS-94 and STS107 appears in Table 1. Complete descriptions of the information obtained from these experiments, along with a summary of the background and motivation for carrying out long term experiments at microgravity using the orbiting Space Shuttle Columbia, can be found in Refs. $[10,11,14,15]$. The present work will consider data from all three flights but emphasizing results obtained during Flight STS-107. Furthermore, it will only consider present findings concerning soot property state relationships.

Radiation intensity images and laser extinction images obtained at quasisteady periods, when no adjustment to the flame conditions were done by the Space Shuttle crew, and for times reported in Table 1, are shown in Fig. 1.

The implications of the measurements obtained during Space Shuttle Columbia Flights STS-83, STS-94 and STS-107 with respect to the existence of soot property state relationships within nonbuoyant laminar jet diffusion flames, thus making these flames the proper laminar paradigm of soot-containing turbulent diffusion flames, are discussed in this section.

Given the reasonably good evaluation of the prediction of the extended Spalding ${ }^{9}$ analysis of the structure of nonbuoyant round laminar jet diffusion flames, described in Aalburg et al., ${ }^{11}$ it is useful to consider the implications of this theory for other properties of these flames. One important result is illustrated in Fig. 2, which is the luminous boundary for flame 3E94, reproduced here from Aalburg et al. ${ }^{11}$ Also shown is an approximation of the dividing streamline, the streamline that originates from the outermost edge of the burner tube. This streamline was obtained from the Spalding solution ${ }^{9}$ for nonbuoyant flames, modified as follows. The transport rate was taken to be the viscosity of air at $1334 \mathrm{~K}$ (the average of the adiabatic flame temperature and $298 \mathrm{~K}$ ) divided by a Schmidt number of 0.76 . A blending function was introduced to prevent the divergence of streamlines to infinite radius as axial distance approaches zero. The streamline radii were augmented by the factor (1334 / 298) ${ }^{0.5}$ to account for thermal expansion, which was not considered by Spalding. ${ }^{9}$

There are two major types of streamlines (or soot pathlines) that must be considered for flames of this type that are separated by the dividing streamline that bounds the flow beginning at the burner exit from flows induced by entrainment of the jet flow. Internal streamlines originate at the burner exit and external streamlines originate in the ambient environment. Remarkably, as shown in Fig. 3, all the internal streamlines have nearly identical variations of fuel-equivalence ratios as a function of time after leaving the burner exit. This behavior comes about because flows near the burner axis move at the largest velocities but must travel the largest distances to reach a given value of the fuel-equivalence ratio whereas flows near the dividing streamline move at the smallest velocities but also travel the smallest distances to reach a given value of the fuel-equivalence ratio. Furthermore, this result is independent of the. 


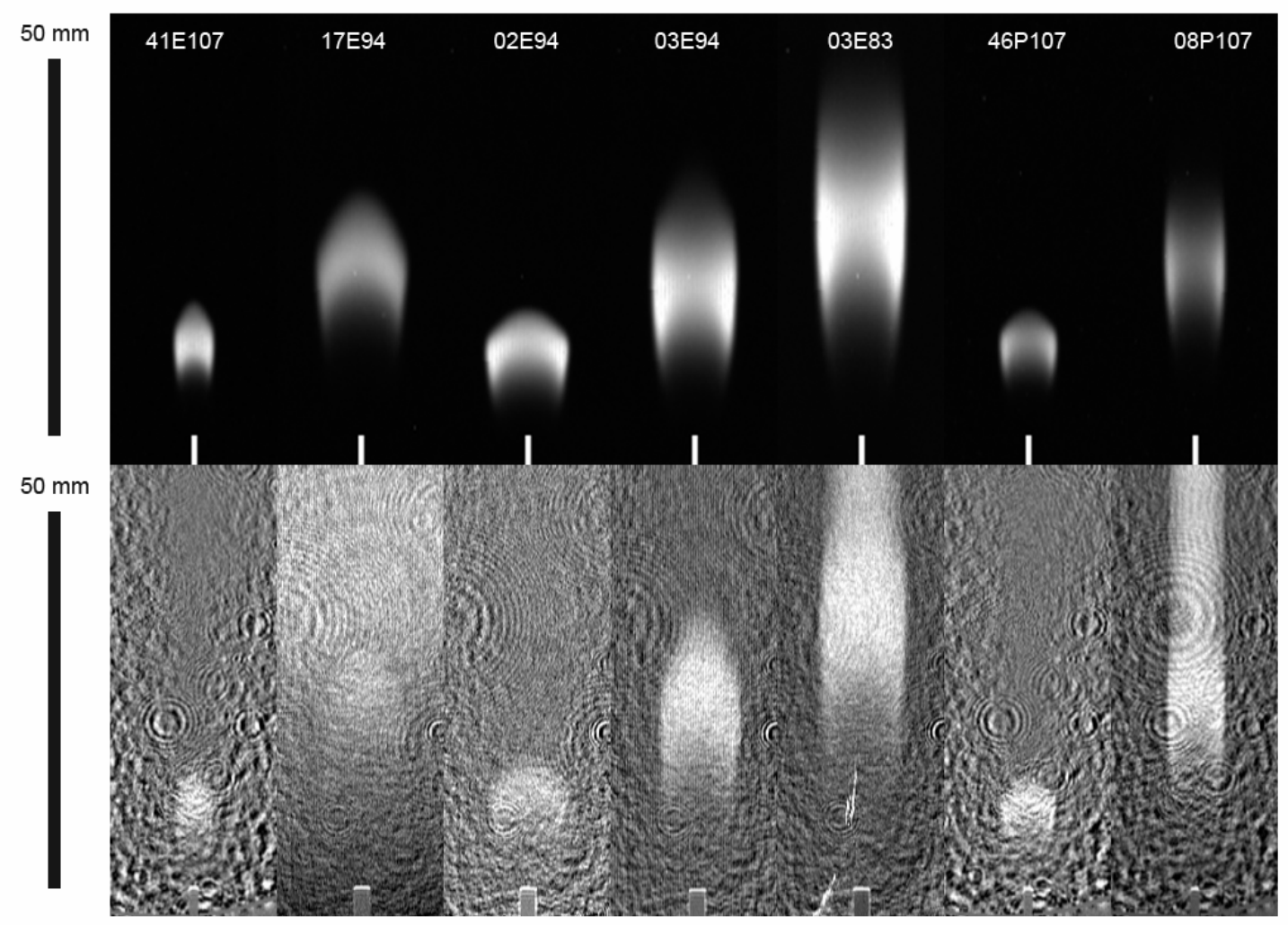

Figure 1. Assembled soot emission images (top) with soot volume fraction images via laser extinction images (bottom) for each of the flames deconvoluted in this paper. The images correspond vertically for each flame and were taken at the times indicated in Table 1. The soot emission images were taken with a $650 \mathrm{~nm}$ filter and the soot volume fraction images were taken using a laser line filter. The laser background (no flame present) was subtracted from each image and each image was separately contrast enhanced. The interference patterns in the laser extinction images are a result of the coherent light source.

initial burner exit velocity because varying these velocities by a factor correspondingly varies distances traveled to reach a particular of fuel-equivalence ratio by the same factor

On the other hand, external streamlines exhibit a variety of behaviors involving the variation of the fuelequivalence ratio as a function of time; fortunately, these streamlines are confined to fuel-lean conditions with correspondingly small soot concentrations that do not have a large impact on the soot properties of practical flames. It is already well known, that nearly adiabatic soot-containing laminar diffusion flames exhibit state relationships for scalar properties (i.e., Faeth and Samuelsen ${ }^{1}$, Gore and Faeth ${ }^{2}$ ). The observations of Fig. 2 imply that the reaction environments of soot passing along different internal streamlines, with various initial velocities, should also be identical functions of time for nonbuoyant flames.

Figure 3 shows a hypothesized state relationship for residence time in nonbuoyant gas jet flames. The equation and curve shown for the centerline residence time come from an integration of the velocity solution of Spalding. ${ }^{9}$ Also shown is the estimated residence time of the dividing streamline of Fig. 3. All internal streamlines (those originating from the burner tube) are bounded by these two curves. Also shown is the estimated residence time of a sample external streamline. External streamlines cross the flame sheet twice and here are normalized to zero time at their first crossing point. Recalling that scalar gaseous properties in soot-containing laminar jet diffusion flames satisfy state relationships (including temperatures) as long as characteristic flame residence times are short enough so that radiant heat losses are small, this behavior implies that the reactive environment of soot particles along all paths through the flame are identical functions of time for given initial flame reactant compositions, temperatures and pressures. As a result, nonbuoyant laminar diffusion flames should exhibit universal soot properties as a function of mixture fraction, for given initial flame reactant compositions, temperatures, and pressure, as required for the presence of soot property state relationships.

Measurements of the soot temperatures and soot volume fractions of the seven attached flames of Table 1 are shown in Figs. 4 - 5. These figures present radial distributions at selected axial distances. Measurements are 


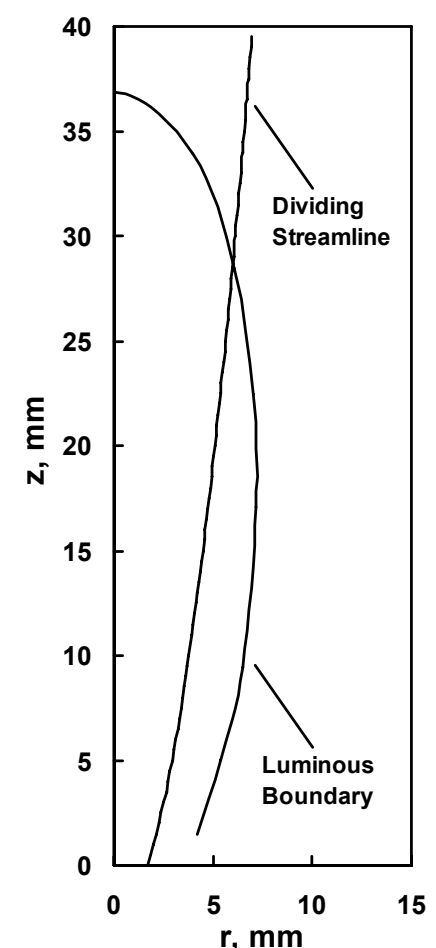

Figure 2. Measured luminous boundary from video image and predicted dividing streamline for flame 3E94. The dividing streamline is the streamline emerging at the burner tip and was developed by extending the model of Spalding. ${ }^{9}$

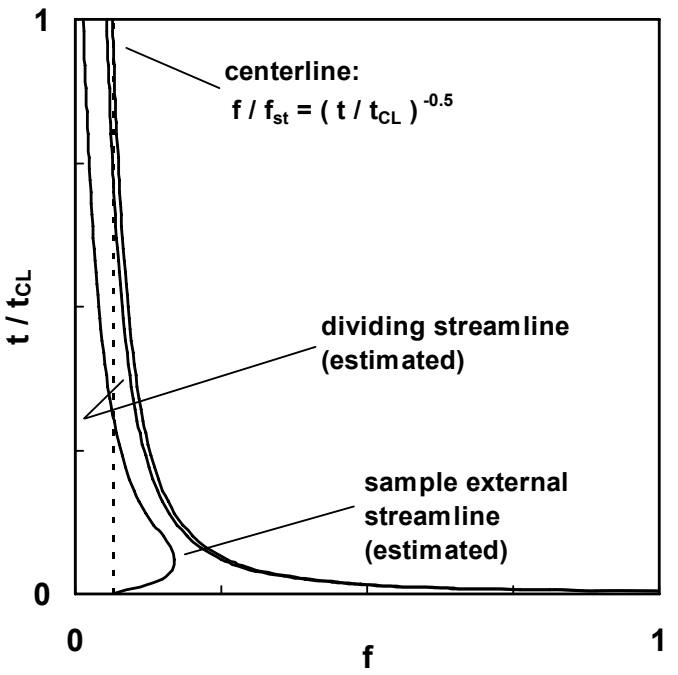

Figure 3. Hypothesized residence time state relationship for internal streamlines. The abscissa is mixture fraction and the ordinate is residence time non-dimensionalized by the centerline residence time. For external streamlines, residence time is referenced to the first crossing of the flame sheet.

available only where soot temperatures and volume fractions are sufficiently high. Measurements generally are not reported near the flame axes, where deconvolution errors lead to high uncertainties.

Radial profiles of both soot temperature and soot volume fraction have peaks off centerline at small axial distances. At larger distances these peaks generally converge to the centerline (e.g., flame 41E107 in Fig. 4), although soot peaks generally do not converge for flames that emit soot (e.g., flame 3E83 in Fig. 5). The peak temperatures of the flames generally decrease with axial distance. This is attributed to radiative losses except at the largest axial distances, where all stations are on the oxidizer side of the flame sheet (e.g., the $z=15 \mathrm{~mm}$ profile of flame 46P107 in Fig. 5).

The measurements of Figs. 4 - 5 suggest the existence of soot state relationships for some regions of these flames. The general behavior of the soot volume fraction measurements (see flame 3E83 in Fig. 5) is that peak soot volume fraction initially increases with height, then reaches a plateau, and finally deceases at axial distances beyond the stoichiometric flame tip. The plateau region is evident for all the flames in Figs. 4 - 5 and strongly suggests the existence of soot state relationships here. Such state relationships are not expected at low axial distances, where heat losses to the burner, air leakage through the flame base, and limited residence time combine to limit soot volume fraction. Most streamlines from the burner exit to the surroundings exhibit nearly the same maximum soot concentration, which follows if the reaction environment is the same function of time for all interior streamlines as discussed in conjunction with Fig. 3.

The potential for state relationships for steady nearly-adiabatic nonbuoyant laminar jet diffusion flames is examined further with the results illustrated in Figs. 6 and 7. On these plots, measurements of peak deconvoluted radiation intensity from the soot at each streamwise location (normalized by the maximum peak radiation intensity for all streamwise locations) is plotted as a function of distance from the burner exit (normalized by the axial distance to the maximum intensity). The results for the attached flames are plotted separately from the lifted flames because the lifted flames show a compressed dependence on axial distance from the nozzle due to the displaced flame base. The regions of the flames away from the influence of burner heat loss show remarkably consistent flame radiation levels. It is evident that the deconvoluted radiation intensity along internal streamlines has relatively 

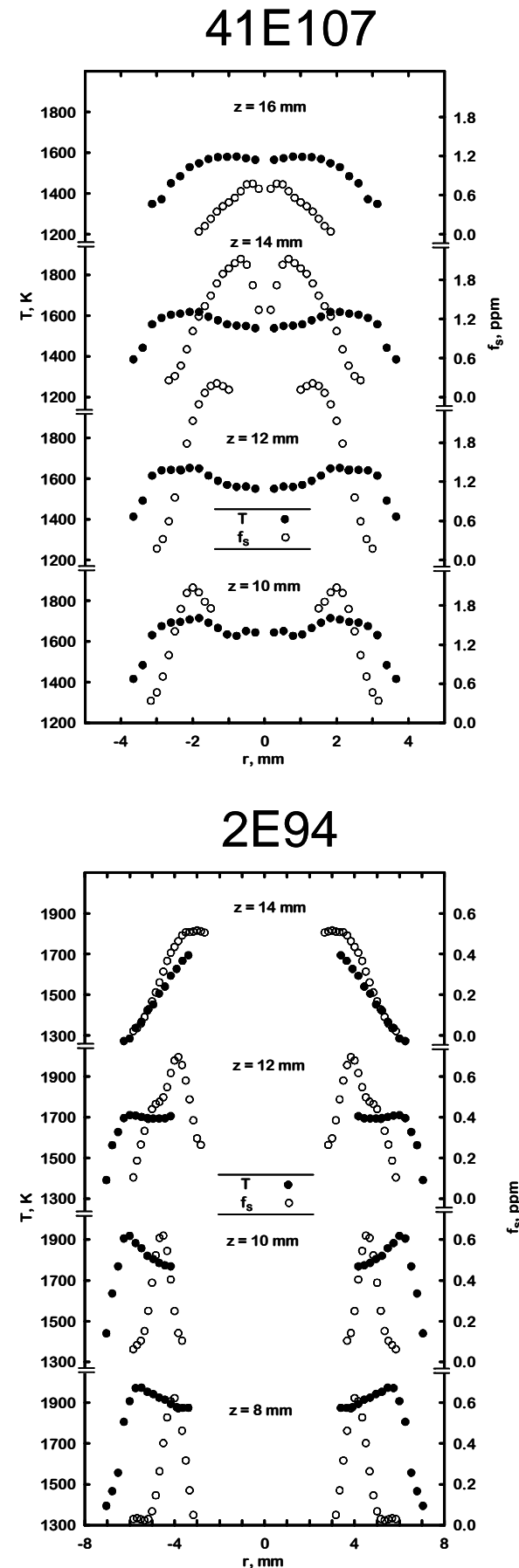
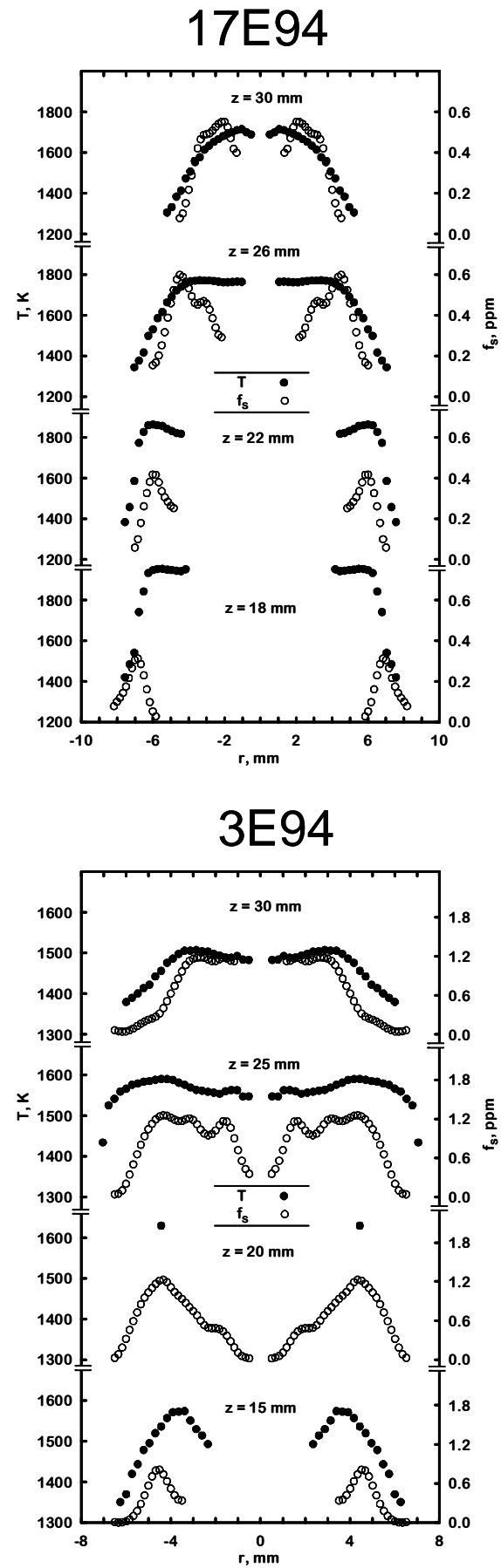

Figure 4: Soot temperature and volume fraction distributions for ethylene flames $41 E 107$ (d=0.8 mm, $100 \mathrm{kPa}), 17 \mathrm{E} 94$ (d=1.6 mm, $35 \mathrm{kPa}), 2 \mathrm{E94}$ (d=1.6 mm, $50 \mathrm{kPa})$, and $3 E 94(\mathrm{~d}=1.6 \mathrm{~mm}, 50 \mathrm{kPa})$.

uniform values, in agreement with the presence of soot property state relationships. Positions near the burner exit, however, involve smaller concentrations of soot, and therefore lower radiation intensities than elsewhere because soot properties are dominated by behavior along external streamlines in this region.

In Figs. 8 and 9, soot state relationships were considered in regions where both soot temperature and soot volume fraction were measured in the present attached flames. In these regions, temperatures were linearly interpolated at the radii of measured soot volume fractions. Locations were considered to be on the fuel side of the 

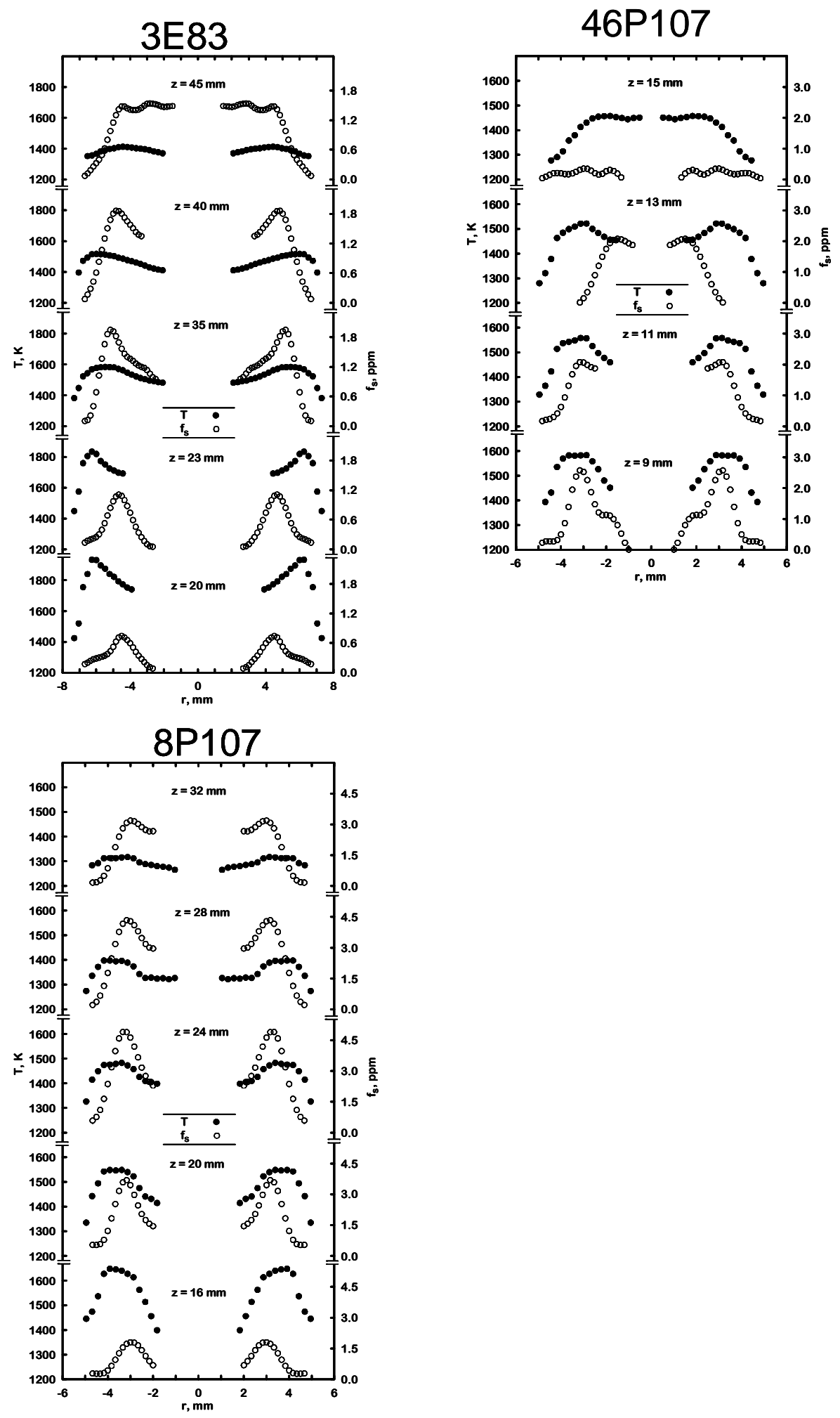

Figure 5: Soot temperature and volume fraction distributions for flames 3E83 $\left(\mathrm{C}_{2} \mathrm{H}_{4}, \mathrm{~d}=1.6 \mathrm{~mm}, 50 \mathrm{kPa}\right), 46 \mathrm{P} 107\left(\mathrm{C}_{3} \mathrm{H}_{8}, \mathrm{~d}=0.8 \mathrm{~mm}, 99 \mathrm{kPa}\right)$, and $8 \mathrm{P} 107$ $\left(\mathrm{C}_{3} \mathrm{H}_{8} \mathrm{~d}=0.8 \mathrm{~mm}, 100 \mathrm{kPa}\right)$. 


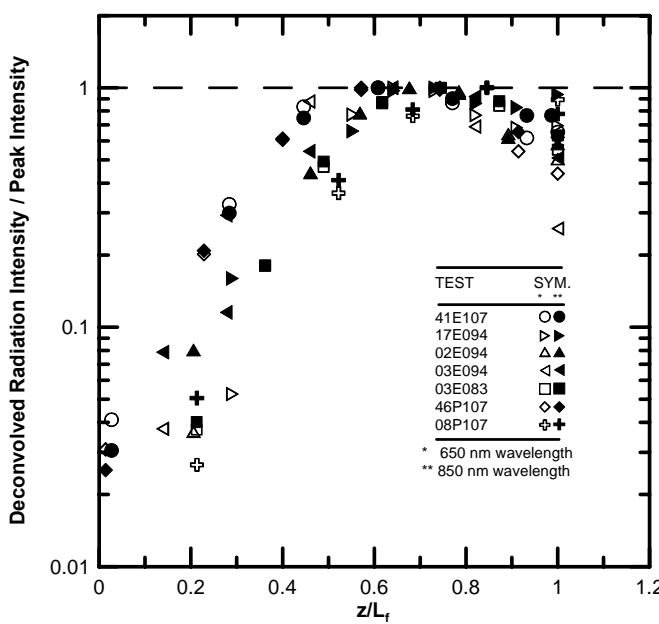

Figure 6. Peak radiation intensity from soot normalized at various streamwise locations, normalized by the maximum peak radiation intensity for the attached flames in Table 1.

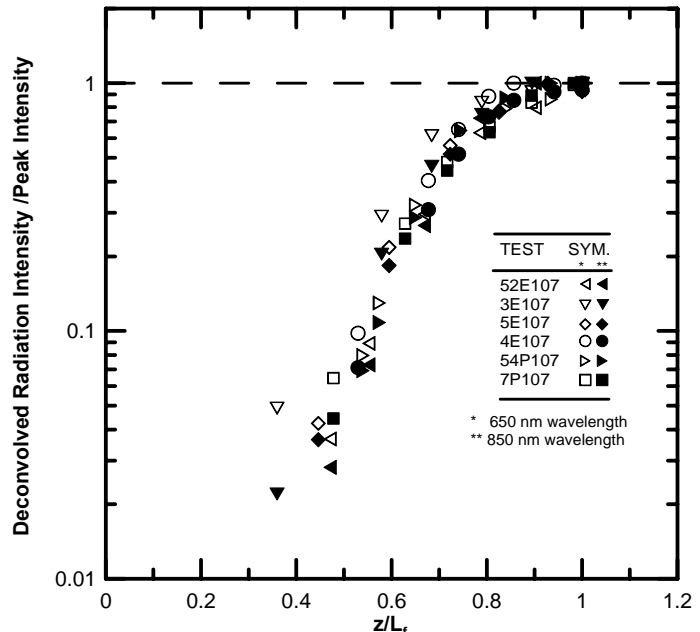

Figure 7. Peak radiation intensity from soot normalized at various streamwise locations, normalized by the maximum peak radiation intensity for the lifted flames in Table 1.

flame if they were inside the contour of peak temperature and to be on the oxidizer side otherwise. The peak temperature was identified at each height in each flame. For heights above the contour of peak temperature, peak temperature was taken as that of the next lower height. Each point for a given height was then converted to estimated mixture fraction using this peak temperature and an assumed linear relationship between temperature and mixture fraction from the theory of Burke and Schumann.

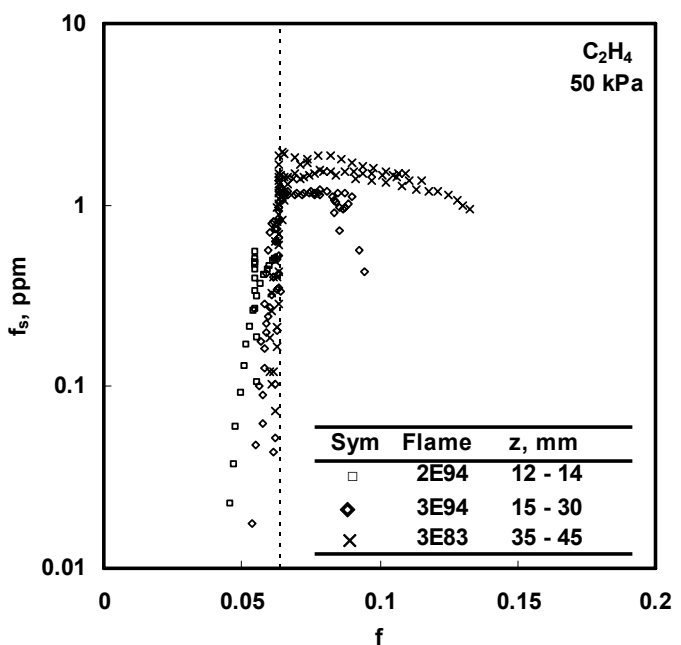

Figure 8. Soot state relationship for the present ethylene flames at $50 \mathrm{kPa}$. The ordinate is the soot volume fraction and the abscissa is the mixture fraction. The vertical dashed line is the flame sheet $\left(f_{s t}=\mathbf{0 . 0 6 3 6}\right)$.

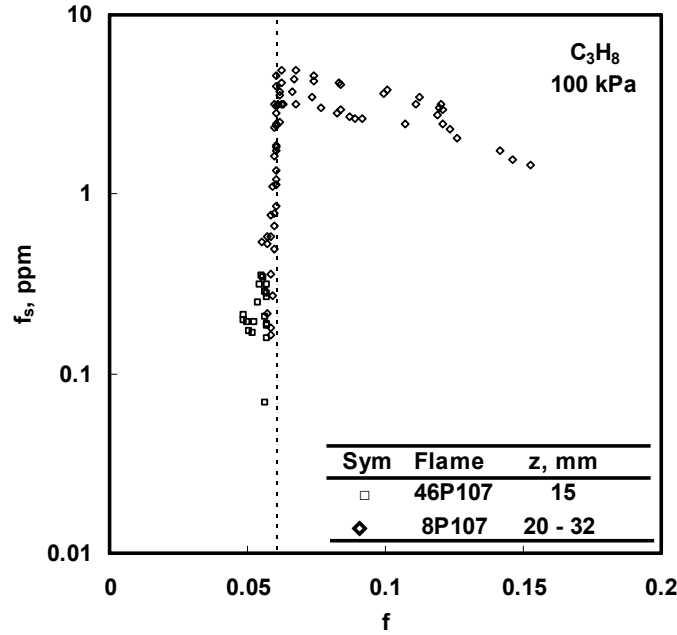

Figure 9. Soot state relationship for the present propane flames at $100 \mathrm{kPa}$. The ordinate is the soot volume fraction and the abscissa is the mixture fraction. The vertical dashed line is the flame sheet $\left(f_{\mathrm{ct}}=\mathbf{0 . 0 6 0 2}\right)$.

Assuming soot relationships exist, a different relationship would be expected for each fuel/pressure combination. Therefore soot state relationships were examined for each fuel/pressure combination among the attached flames of Table 1. Representative results are shown in Figs. 8-9 and similar relationships were found for the other available fuel/pressure combinations. The soot state relationships shown here exclude data from small axial distances from the nozzle, where partial premixing and quenching by the burner tube preclude state relationships. Figures 8-9 reveal peak soot volume fractions near the flame sheet, a steep region on the lean side, and a relatively constant region on the fuel side. These soot state relationships do not extend to very lean regions owing to soot volume fractions that 
were too low to measure, or to very rich regions owing to temperatures that were too low to measure. The correlation of the data in Figs. 8-9 is far better than past soot state relationships in buoyant diffusion flames. ${ }^{2,16}$

\section{Conclusions}

Experimental observations of nonbuoyant round laminar jet diffusion flames were made for the following test conditions: ethylene and propane burning in still air; ambient temperature of $300 \mathrm{~K}$; ambient pressures of 35-100 $\mathrm{kPa}$; jet exit diameters of 0.40-1.6 mm; jet exit Reynolds numbers of 57-671; luminous-flame-length to burnerdiameter ratios of 11-125; and luminous flame lengths of 15.8-63 mm. These observations have yielded the following major conclusions:

1. In the non-buoyant flames studied here, the majority of the flame volume is covered by internal streamlines. In this region, a simplified model suggests the existence of a state relationship for time and consequently suggests a state relationship also exists for soot.

2. Maximum soot volume fractions and flame temperature were similar for all paths from the burner exit through the flame sheet for closed-tip flames having small radiative heat losses. This is a necessary condition for the existence of soot property state relationships for steady nonbuoyant laminar diffusion flames, and thus in practical turbulent diffusion flames through the application of the widely-recognized laminar flamelet concept.

3. In regions not affected by heat loss to the burner, peak radiation intensity does not vary with axial distance. This result further supports the assertion that state-relationship behavior is possible for soot in non-buoyant flames.

4. Soot state-relationship behavior was seen for these flames with soot correlating effectively with mixture fraction (estimated from measured temperature) in the lean and rich zones of these flames.

Since most practical turbulent diffusion flames are nonbuoyant on a local basis, even when the main motion of the flames is caused by effects of buoyancy; therefore, universal soot property state relationships should be observed for a relatively large class of practical soot-containing turbulent diffusion flames.

\section{Acknowledgments}

This research was sponsored by NASA Grant NAG3-2404 under the technical management of the NASA Glenn Research Center. The authors acknowledge the contributions of Ann Over and her associates at the NASA Glenn Research Center for development of the test apparatus and the crews of Space Shuttle Columbia flights STS-83, STS-94, and STS-107, who carried out assembly of the test apparatus and performed the experiments on orbit.

\section{References}

${ }^{1}$ Faeth, G.M. and Samuelsen, G.S., "Fast-Reaction Nonpremixed Combustion,” Progress in Energy and Combustion Science, Vol. 12, pp. 305-372, 1986.

${ }^{2}$ Gore, J.P. and Faeth, G.M., "Structure and Radiation Properties of Luminous Turbulent Acetylene/Air Diffusion Flames," Journal of Heat Transfer, Vol. 110, pp. 173-181, 1988.

${ }^{3}$ Faeth, G.M., "Homogeneous Premixed and Nonpremixed Flames in Microgravity: A Review," Proceedings of the AIAA/IKI Microgravity Science Symposium-Moscow, AIAA, Washington, pp. 281-293, 1991.

${ }^{4}$ Law, C.K. and Faeth, G.M., "Opportunities and Challenges of Combustion in Microgravity," Progress in Energy and Combustion Science, Vol. 20, pp. 65-113, 1994.

${ }^{5}$ Faeth, G.M. “Gaseous Laminar and Turbulent Diffusion Flames,” Microgravity Combustion Science (edited by H.D. Ross), Academic Press, New York, pp. 83-182, 2001.

${ }^{6}$ Sunderland, P.B., Mortazavi, S., Faeth, G.M. and Urban, D.L., "Laminar Smoke Points of Nonbuoyant Jet Diffusion Flames,” Combustion and Flame, Vol. 96, pp. 97-103, 1994.

${ }^{7}$ Sunderland, P.B., Koylu, U.O. and Faeth, G.M., "Soot Formation in Weakly Buoyant Acetylene-Fueled Laminar Jet Diffusion Flames Burning in Air,” Combustion and Flame, Vol. 100, pp. 310-322, 1995.

${ }^{8}$ Sunderland, P.B. and Faeth, G.M., "Soot Formation in Hydrocarbon/Air Laminar Jet Diffusion Flames," Combustion and Flame, Vol. 105, pp. 132-146, 1996.

${ }^{9}$ Spalding, D.B., Combustion and Mass Transfer, Pergamon, New York, pp. 185-194, 1979.

${ }^{10}$ Urban, D.L., Yuan, Z.-G., Sunderland, P.B., Linteris, G.T., Voss, J.E., Lin, K.-C., Dai, Z., Sun, K. and Faeth, G.M., “Structure and Soot Properties of Nonbuoyant Ethylene/Air Laminar Jet Diffusion Flames,” AIAA Journal, Vol. 36, pp. 13461360, 1998.

${ }^{11}$ Aalburg, C., Diez, F.J., Faeth, G.M., Sunderland, P.B., Urban, D.L. and Yuan, Z.-G., "Shapes of Nonbuoyant Round Hydrocarbon-Fueled Laminar Jet Diffusion Flames in Still Air,” Combustion and Flame, Vol. 142, pp. 1-16 2005.

${ }^{12}$ Greenberg, P.S. and Ku, J.C., “Soot Volume Fraction Imaging,” Applied Optics, Vol. 36, No 22, 1997, pp 5514-5522.

${ }^{13}$ Dalzell, W.H. and Sarofim, A.F. “Optical Constants of Soot and Their Application to Heat Flux Calculations,” Journal of Heat Transfer, Vol. 91, pp. 100-104, 1969. 
${ }^{14}$ Lin, K.-C., Faeth, G.M., Sunderland, P.B., Urban, D.L. and Yuan, Z.-G., "Shapes of Nonbuoyant Round Luminous Hydrocarbon/Air Laminar Jet Diffusion Flames,” Combustion and Flame, Vol. 116, pp. 415-431, 1998.

${ }^{15}$ Urban, D.L., Yuan, Z.-G., Sunderland, P.B., Lin, K.-C., Dai, Z. and Faeth, G.M., "Smoke-Point Properties of Nonbuoyant Round Laminar Jet Diffusion Flames,” Proceedings of the Combustion Institute, Vol. 28, pp. 1965-1972, 2000.

${ }^{16}$ Gore, J.P. and Faeth, G.M., "Structure and Spectral Radiation Properties of Turbulent Ethylene/Air Diffusion Flames," Proceedings of the Combustion Institute, Vol. 21, pp. 1521-1531, 1986. 